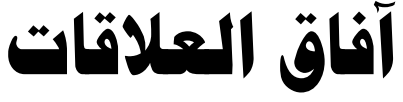

\section{الإسرائيلية - العندية}

\section{هركز الاهرام للدراسات أسعيد عكاشهيه السية والاستراتيجية}

في تقرير نشرته الإنديان إكسبرسIndian express للتعليق علي زيارة رئسبـس

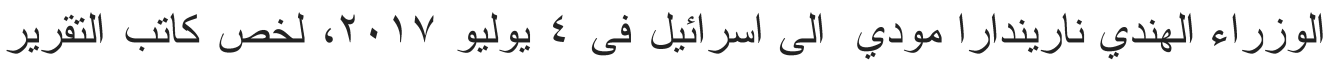

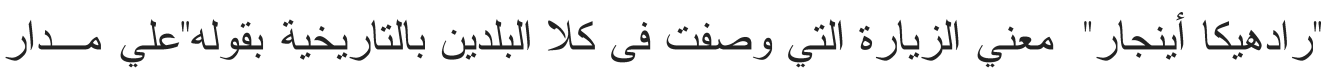

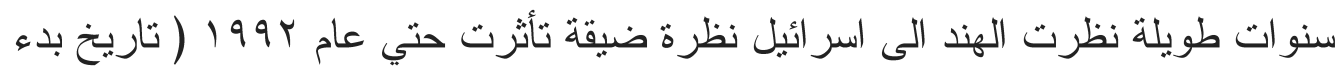

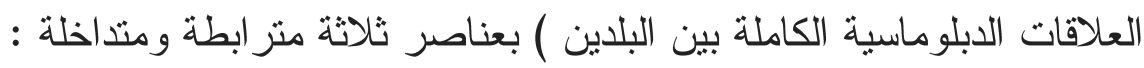

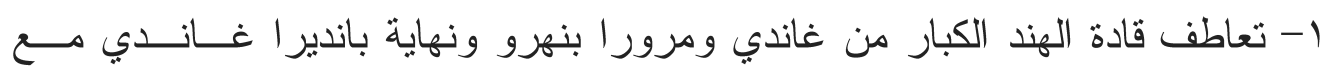

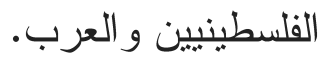

r- التأثير ات التي تركتها الحرب الباردة علي سياسة الهند الخارجية.

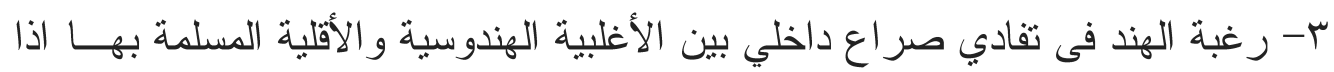
ما أقامت علاقات طبيعية بإسر ائيل".

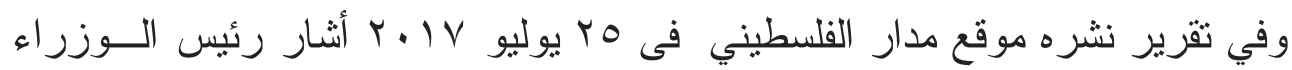

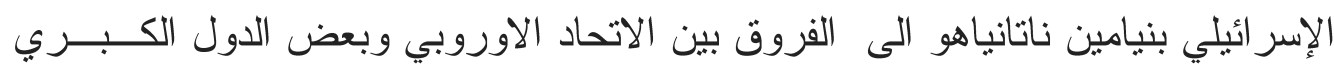

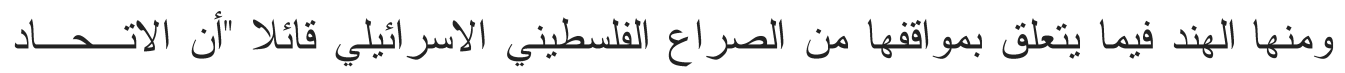

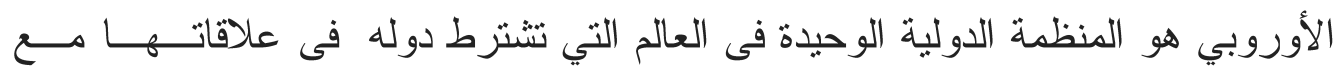

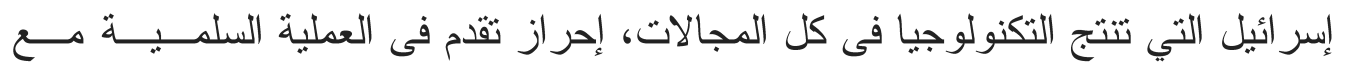

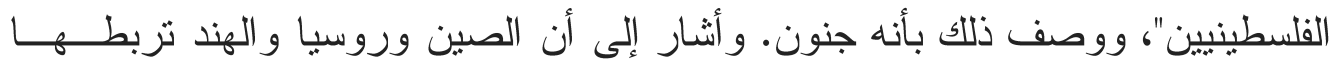

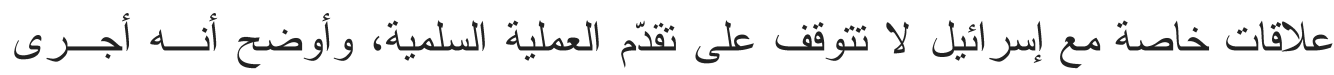




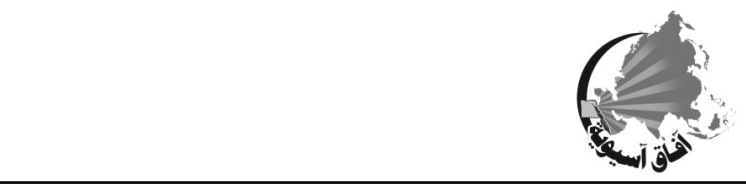

محادثات مع قادة هذه الدول قالو ا فيها إنهم معنيون بما لاى إسر ائيل لتقدمه لهم متجاهلين القضية العالقة مع الفلسطينيين. يعكس النقرير ان و اقع التحولات التي جرت فى العلاقات الهندية الاسر ائيلية من خلال

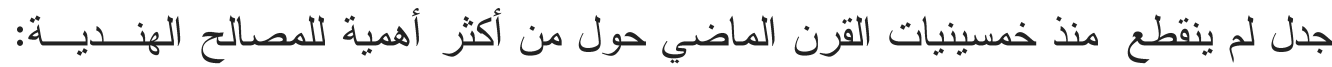

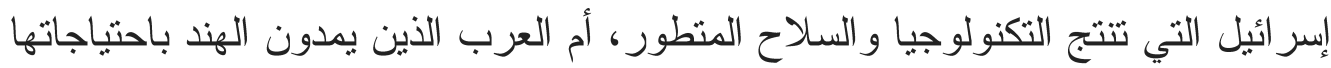

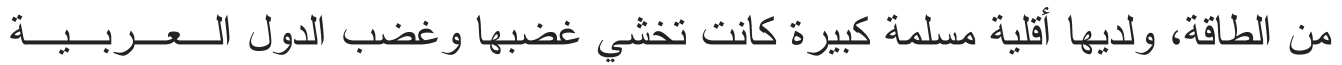

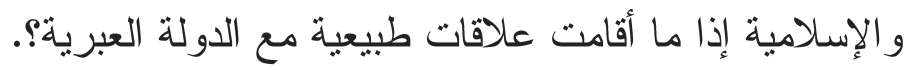

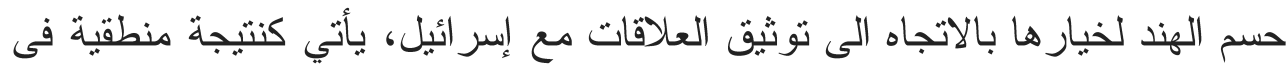

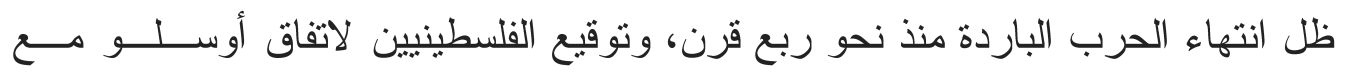

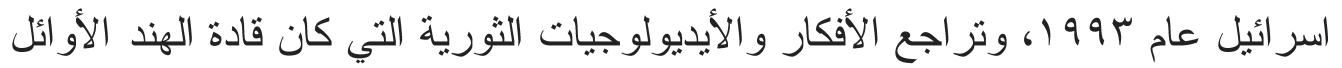

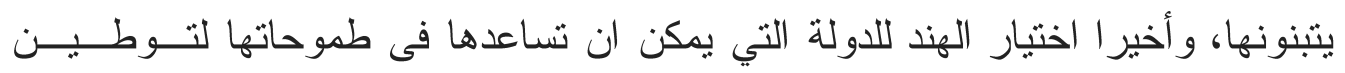

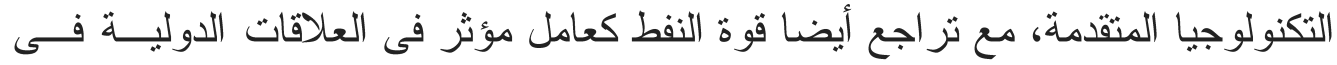

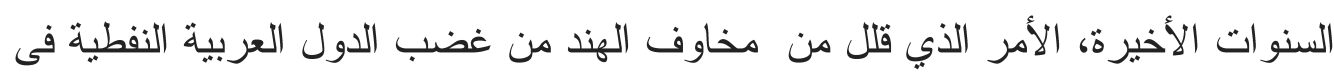
حالة إقامتها علاقات كاملة مع تل أبيب. و السؤال الذي يطرح نفسه الآن ماهي آفاق العلاقات الهندية - الآسر ائيلية مستقبــالـا؟

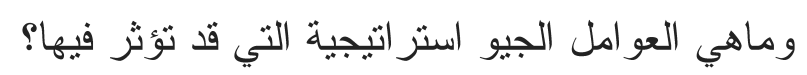

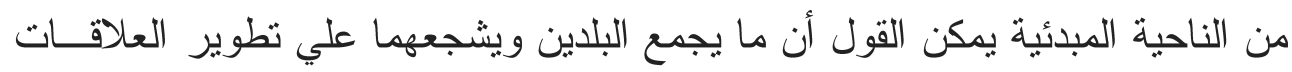

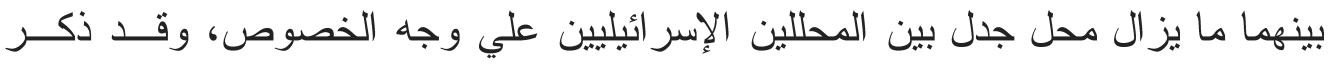

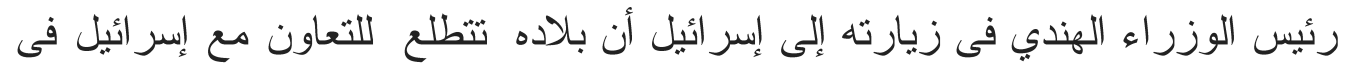

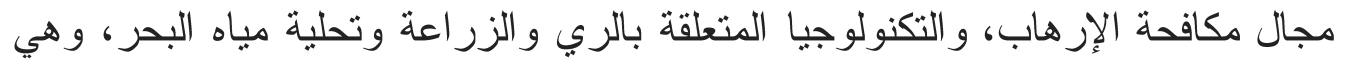

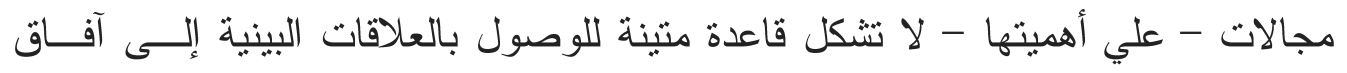

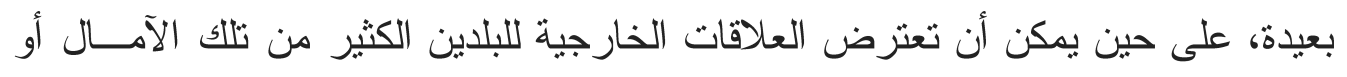

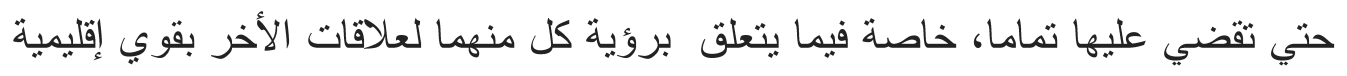
ودولية منل إيران، وروسيا و الصين. وقبل أن نبين مدي تعقد وتشابك هذه الرؤي، سنبدأ أو لا ببحث آفاق العلاقات بينهـــا 


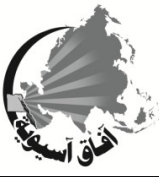

بإفتر اض عدم تأثثير علاقة كل منهما بالقوي الأقليمية و الدولية المُشنار اليها علي علاقتهما

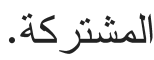

\section{علاقات جيدة ولكن غير متتوازنة}

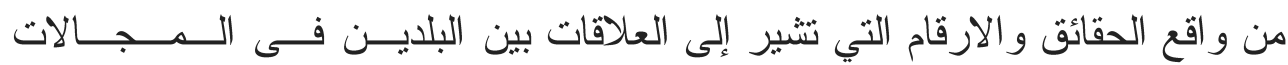

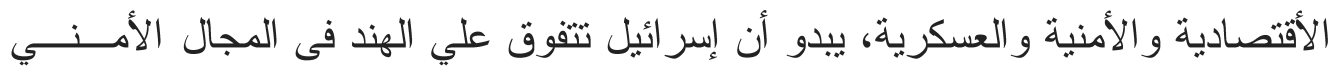

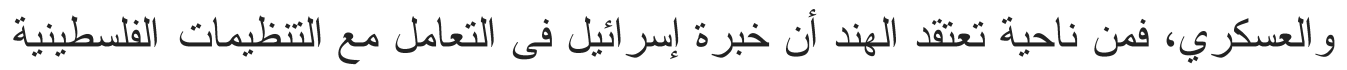
وتتظيم حزب اله من خلال الحروب و المو اجهات التي جرت بينهما، يمكن أن تستقيد منها

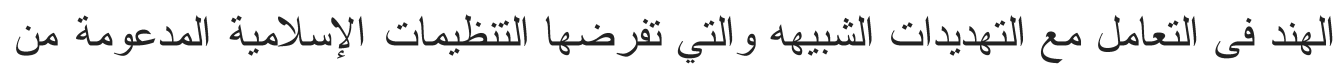
باكستان فى إقليم كثمير ( اقليم متتازع عليه بين البلدين منذ استقلال الهند و انفـــــــال

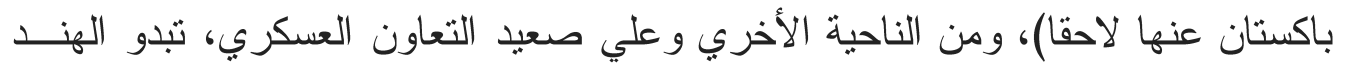

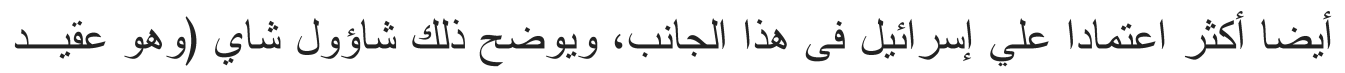

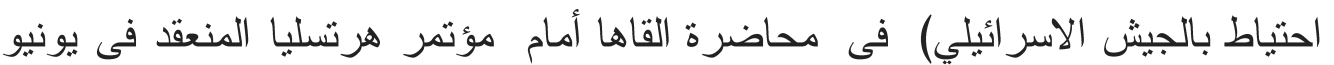

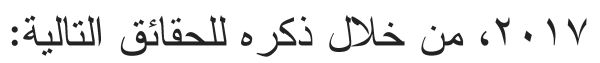
رغبة الهند فى تتويع مصادر تزودها بالأسلحة، وفي الحصول على تكنولوجيا أفضل،

$$
\text { وفي المشاركة فى تطوير و إنتاج عتاد عسكري. }
$$

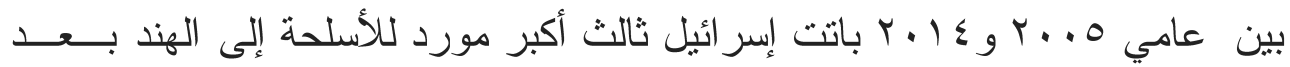

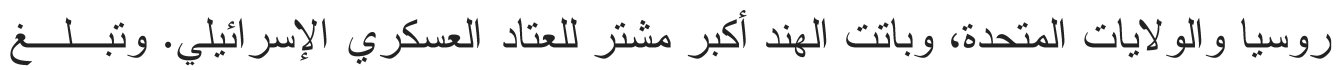

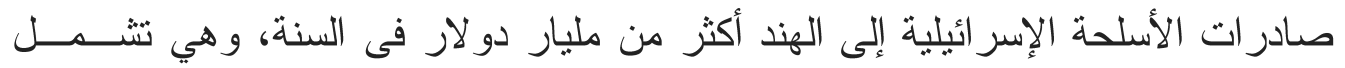

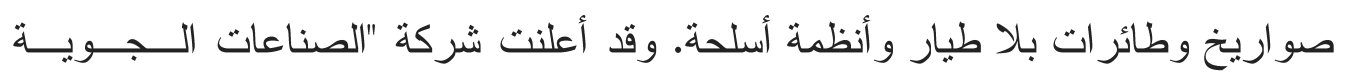

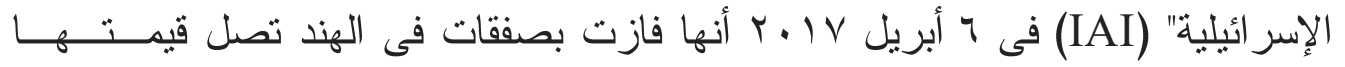

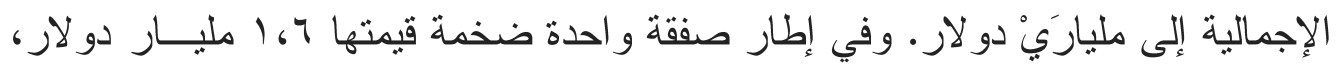

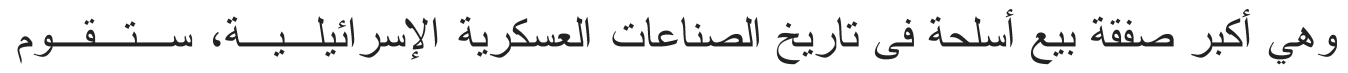

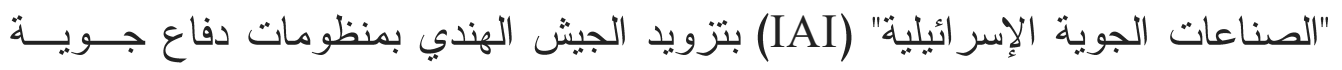

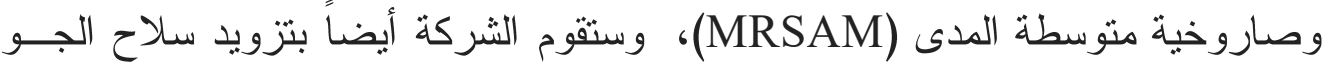

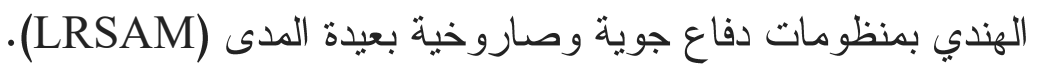




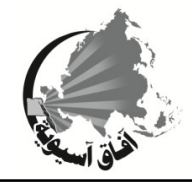

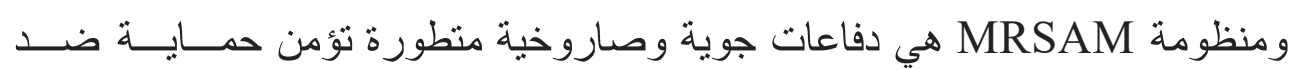

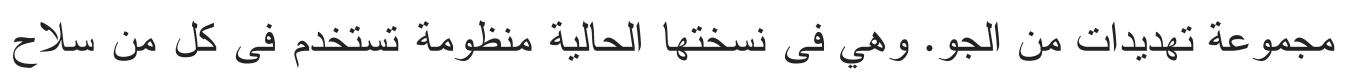

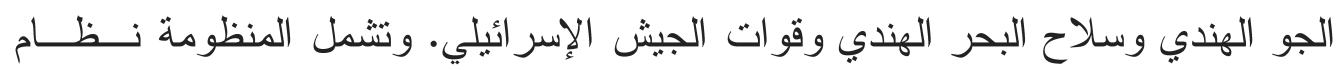

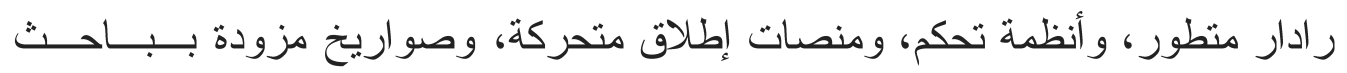

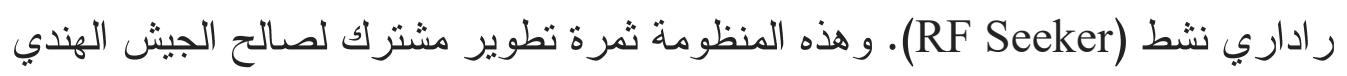

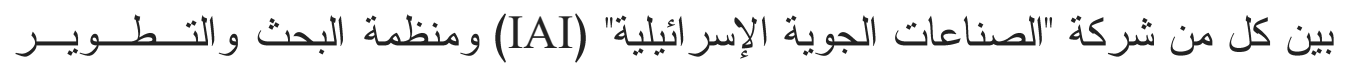

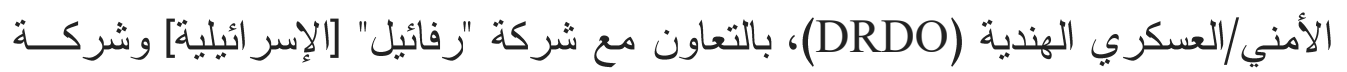

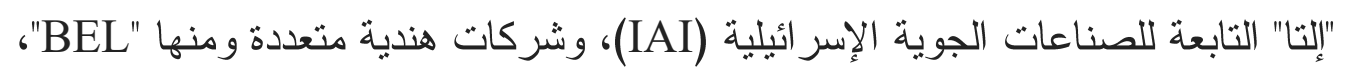

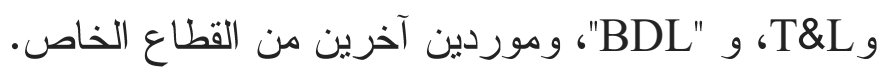

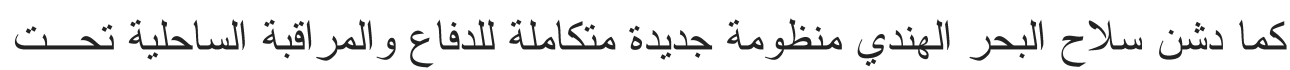

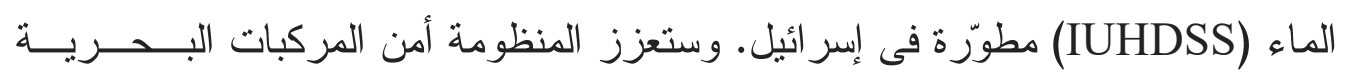
العاملة فوق الماء وتحته التي نتغلها البحرية الهندية فى ميناء "مومباي" البحري.

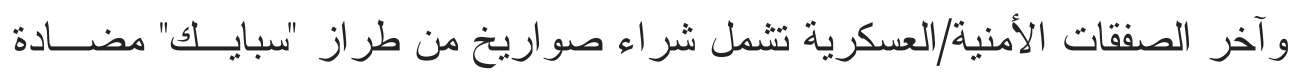

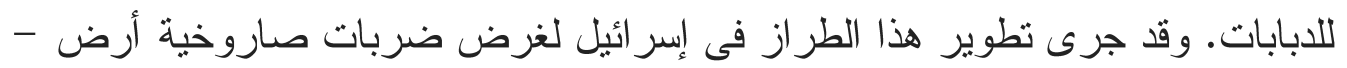

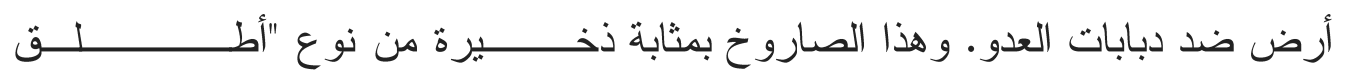

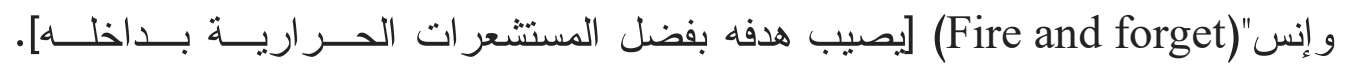

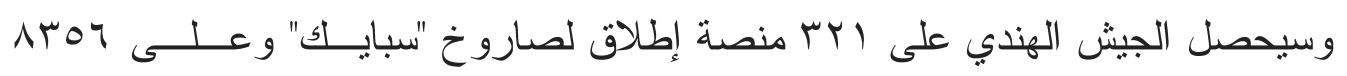

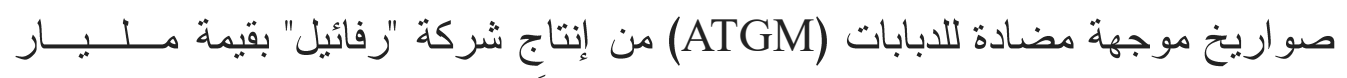

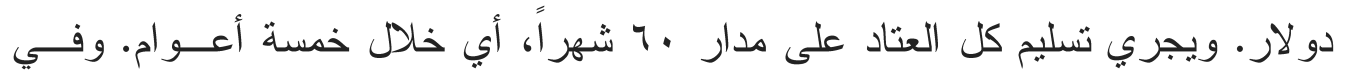

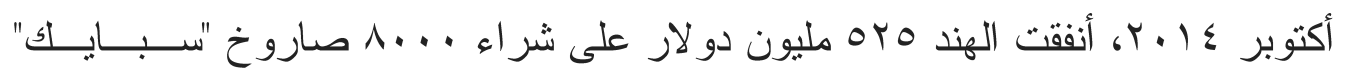
مضاد للابابات و . . ب منصة إطلاق. أما العلاقات التجارية بين البلاين فيمكن تلخيصها ايضا فى النقاط التالية :

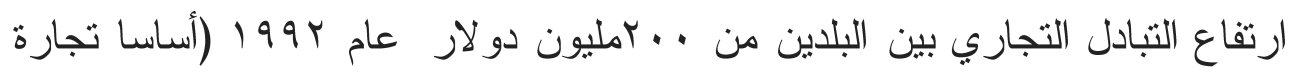

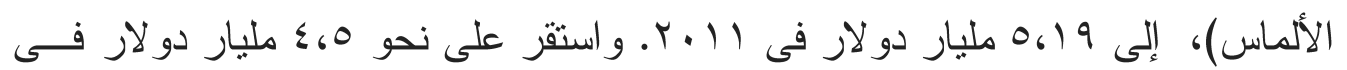
السنة منذ ذلك الحين (باستثناء صادر ات الأسلحة). 


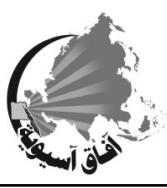

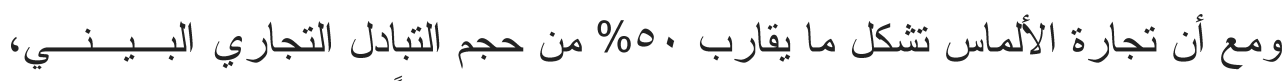

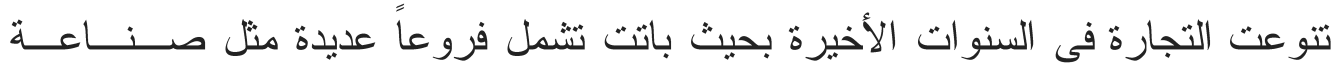

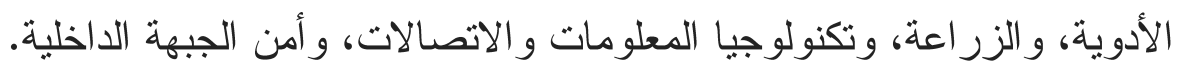

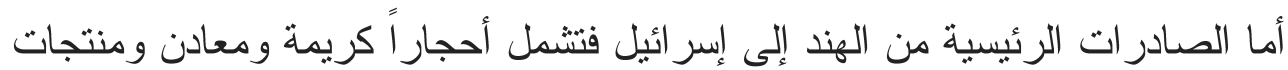

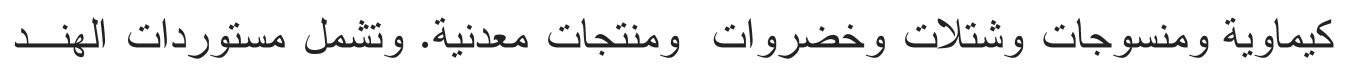

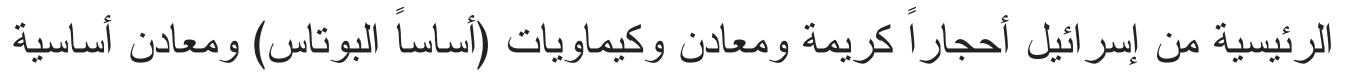
و آليات ومعدات نقل.

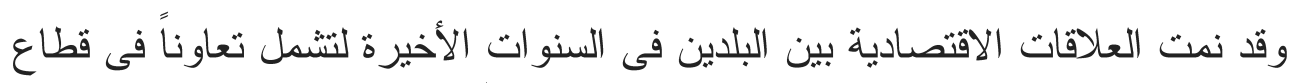

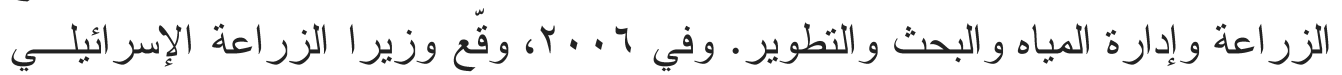

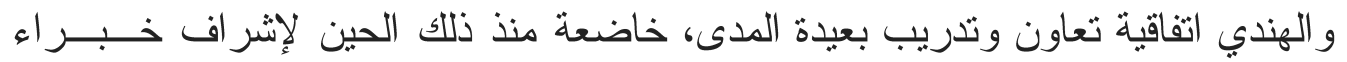

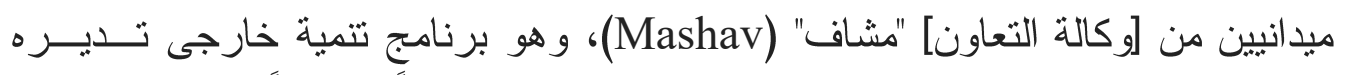

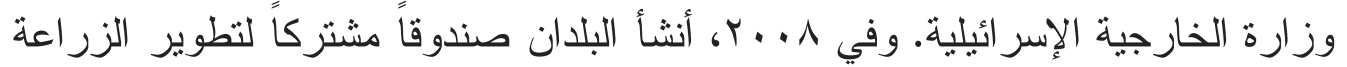

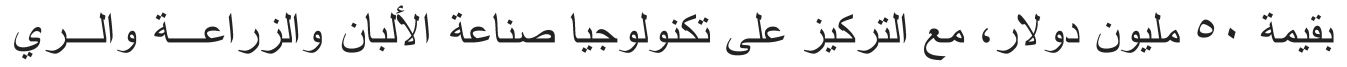

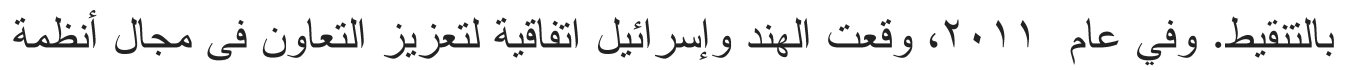

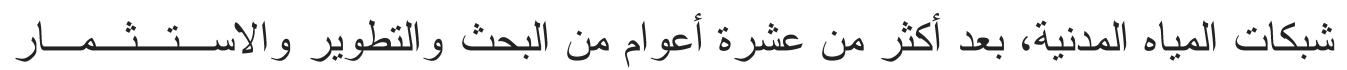

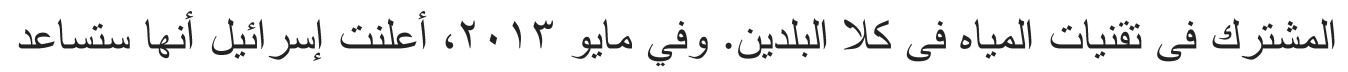

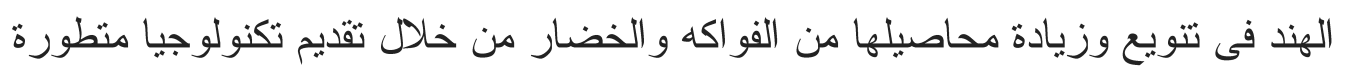

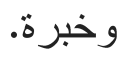
وتجري الدولتان مفاوضات ثنائية بهدف توقيع اتفاقية للتجارة الحرة [إلغاء التعريفات

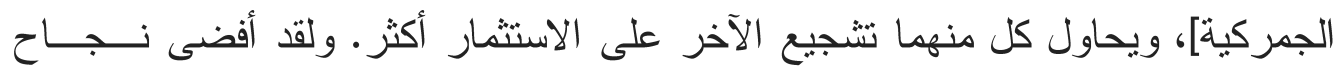

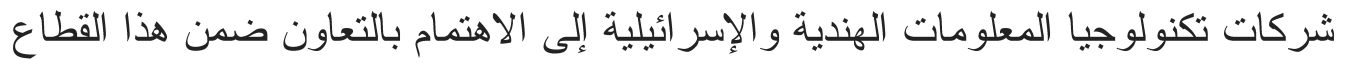
على وجه الخصوص. وتحاول الحكومتان زيادة التفاعل البيني من خلال تبادل البعثات التعليمية و السياحية،

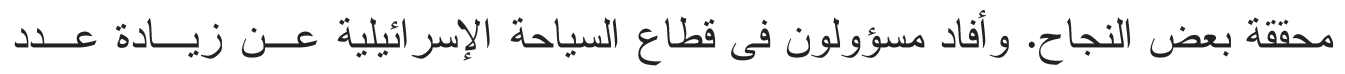

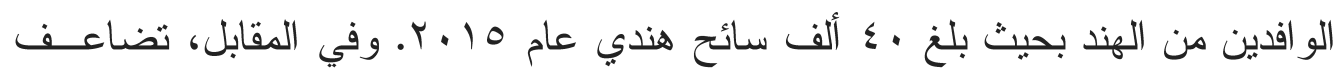

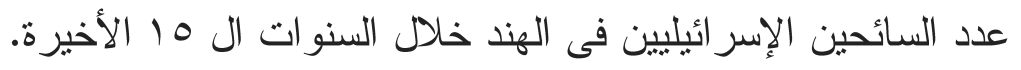




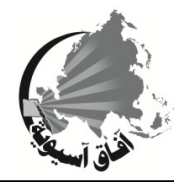

كما تعاونت الدولتان سابقا فى مجال تكنولوجيا و أبحاث الفضاء. ففي نوفمبـر r . . Y ،

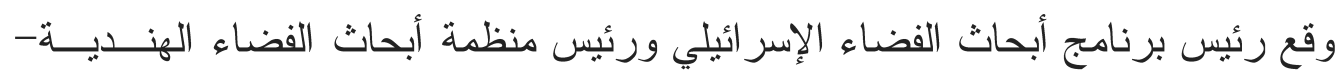
"ايسرو" (ISRO) اتفاقية تعاون فى مجال الفضاء بين البلدين. وفي عام A . . ب أطلقت

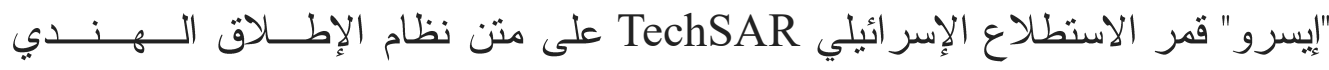

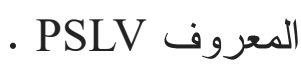

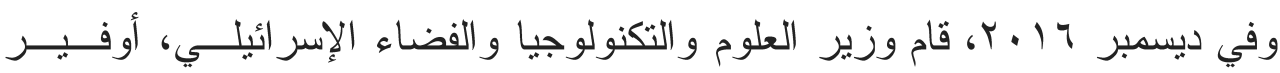
أكونيس، بزيارة إلى الهند مدتها أربعة أيام، وكانت الغاية منها دفع مشاريع بحث وتطويز وتطوير مشتركة فى مجال التكنولوجيا و العلوم التطبيقية ومن ضمنها شر اكات فضاء فى مجالات مر اقبة كوكب الأرض و الاتصالات و الدفع الصاروخي. ومن واقع النقاط السالفة الذكر يبدو بوضوح ان احتياج الهند لاسر ائيل أكبر، وهو مالأن يعطي تل أبيب قدرة أكبر علي التحكم فى وثيرة تطوير العلاقات بينهما بإفتر اض عـدم دخول مؤثزات اخري فى هذه العلاقة، غير أن الأمور لن تسير علي هذا النحو، فلكل من لن

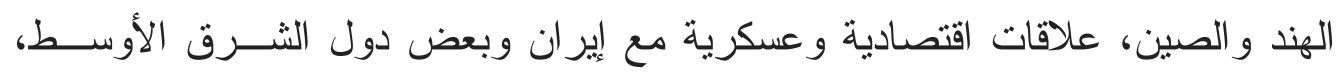

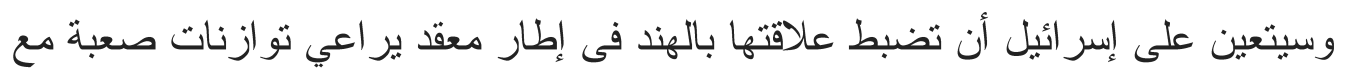

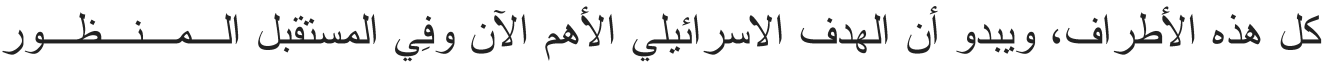
و المتوسط، هو منع إيران من التقارب مع آي من الدول الكبري الثناث (الهند، و الصين، وروسيا) خاصة فى المجال الأمني و العسكري الذي يؤثز علي مصالح إسر ائيل الأمنية، فكيف ستوازن إسر ائيل علاقتها بالهند دون أن يؤدى ذلك إلى قيام الصين وروسيا بتقديم الاعم التكنولوجي و العسكري لإيران، وهى الخصم الأكبر لإسر ائيل؟

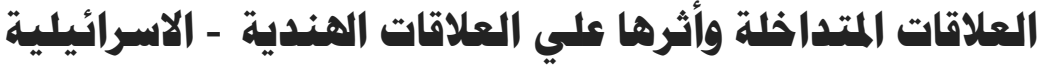

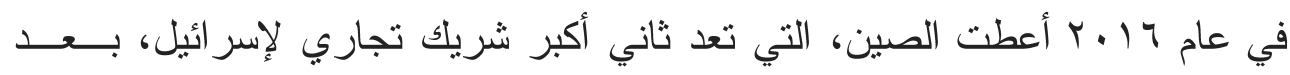

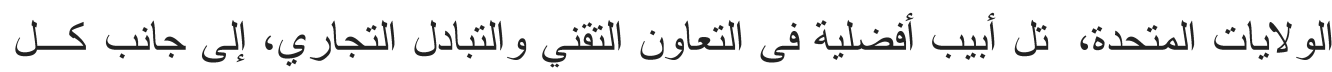

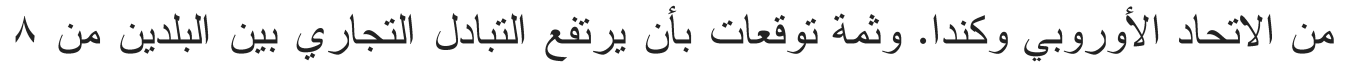
مليار دو لار عام 10 • ب الى الضعف فى هذا العام، وهو نفس مستوي التبادل التجــاري الذي تطمح الهند أن تحققه مع اسر ائيل. وسيحقق زيادة التبادل التجاري بين إسر ائيـلـ و الصين منفعة منبادلة للبلدين، حيث تسعى الثركات الصينية إلى شراء التكنولوجيـات 


\section{6.}

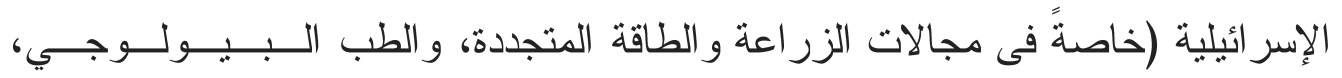

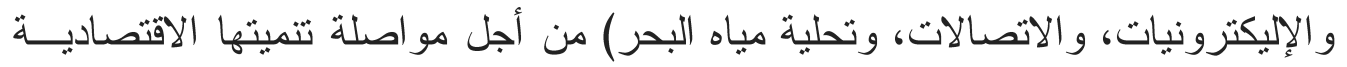

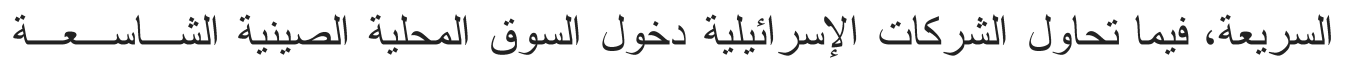

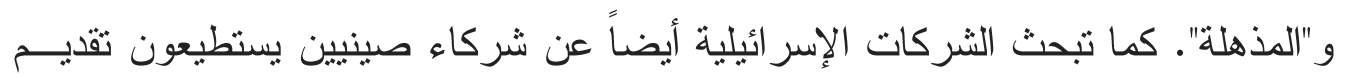

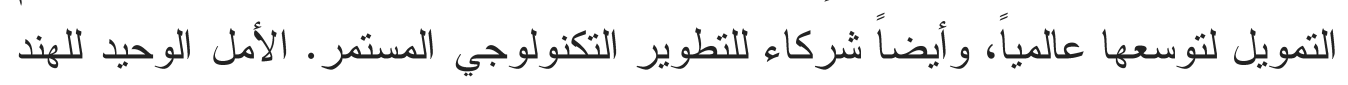

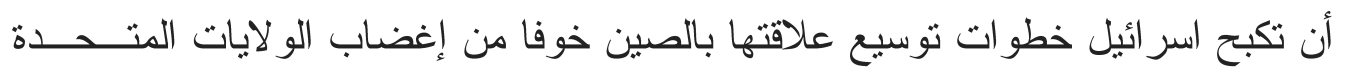

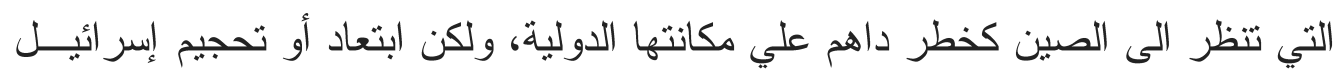

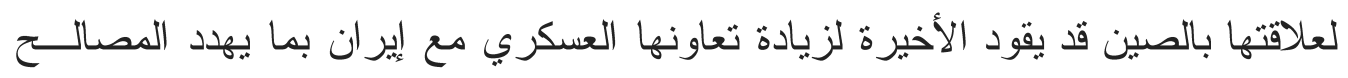

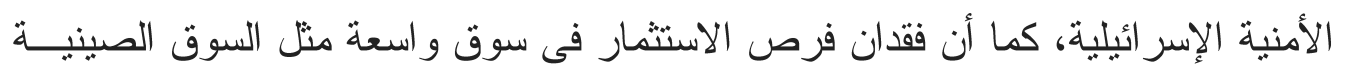

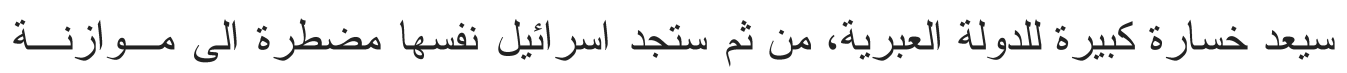

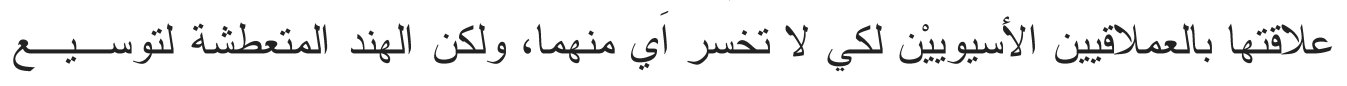

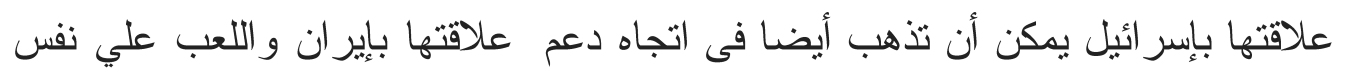

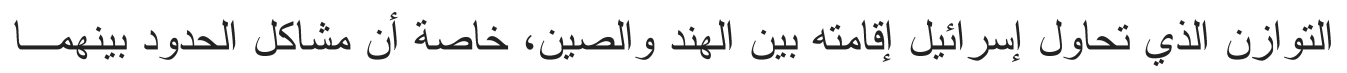

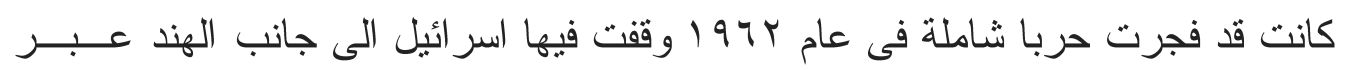
مدها بصفقات سلاح سرية.

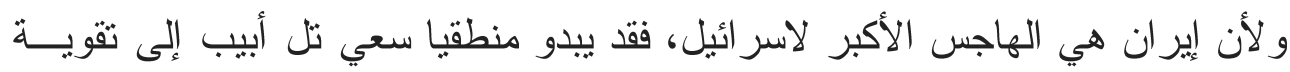

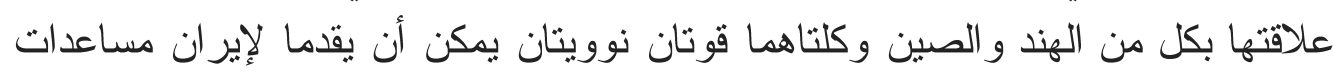

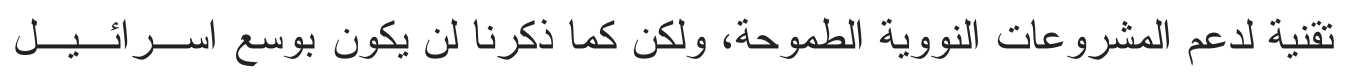

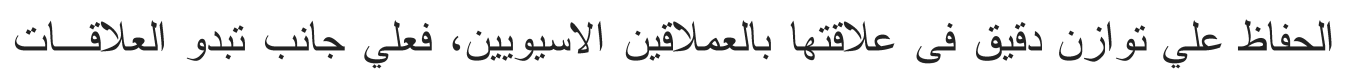

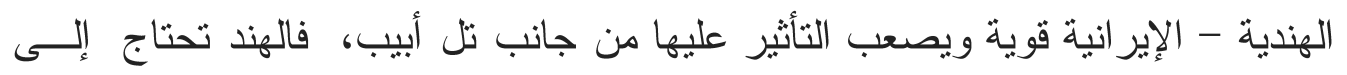

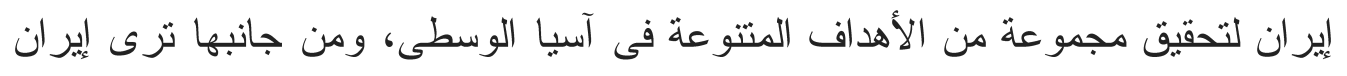

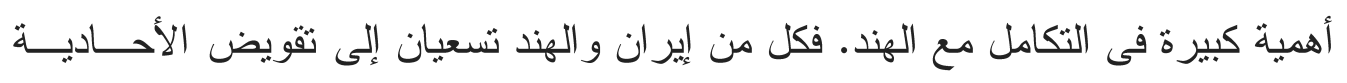

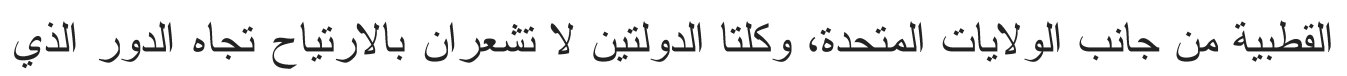

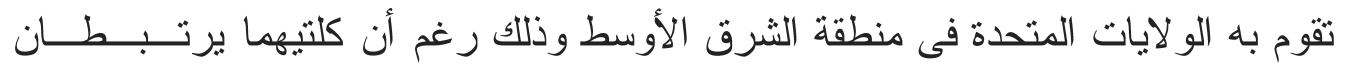

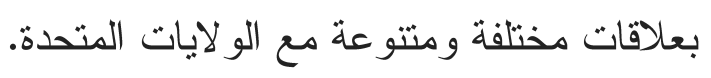
وكل من إيران و الهند يتشاطر ان القلق إزاء الحالة الأمنية الداخلية فـى دول آســــــا. 


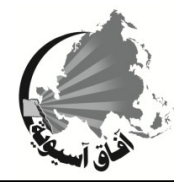

الوسطى، وذلك نتيجة لخوفهما المشترك من تجدد نفوذ الإسلاميين السُنة فى أفغانستــان

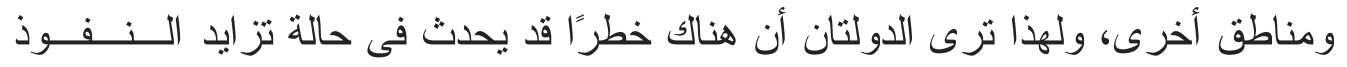

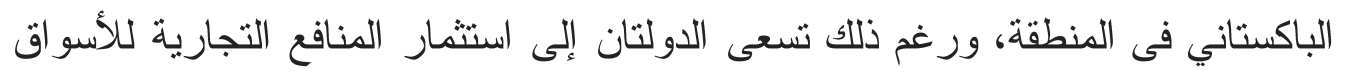

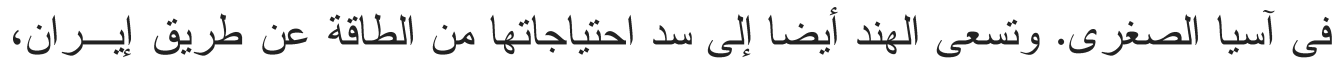

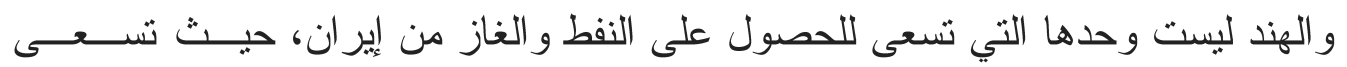

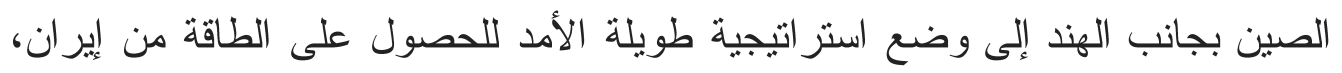

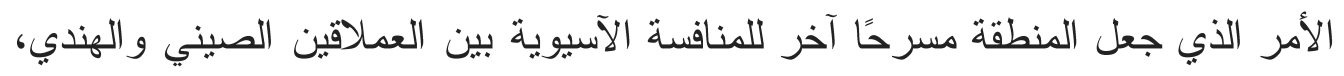

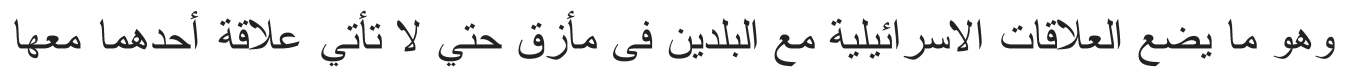

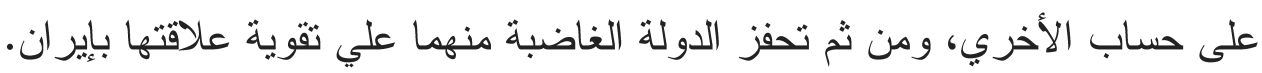

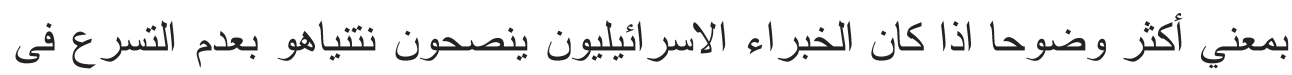

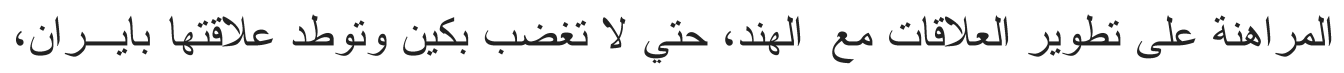

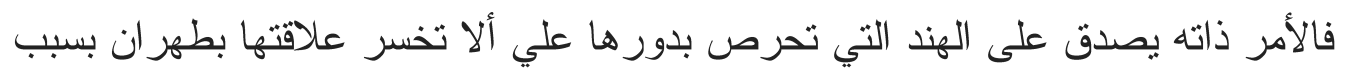

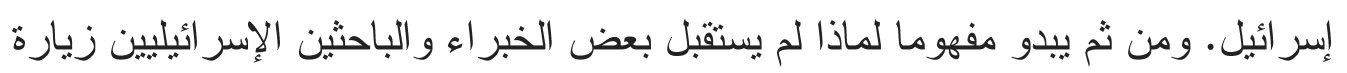

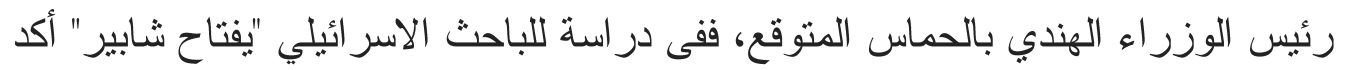

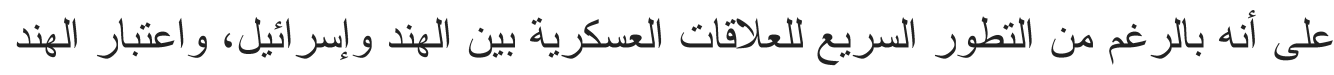

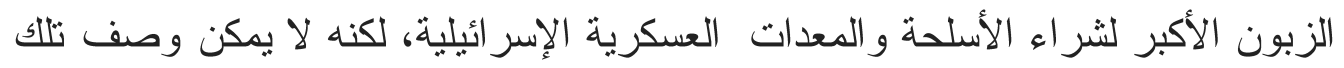
العلاقات بأنها علاقات استر اتيجية من الدرجة الأولى، خاصة وأن الأن الهند تتطلع للاستقلال

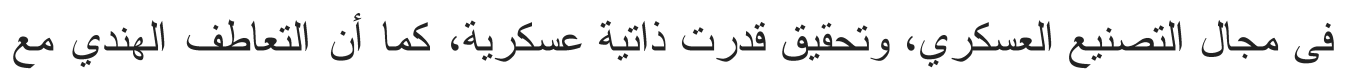

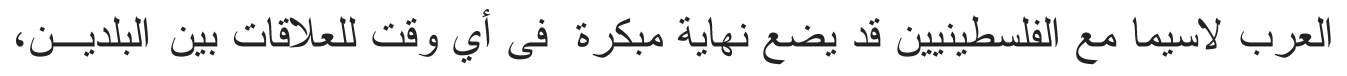

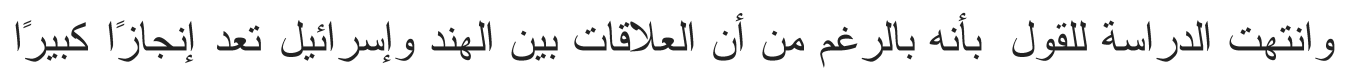

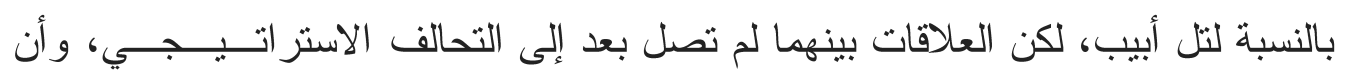

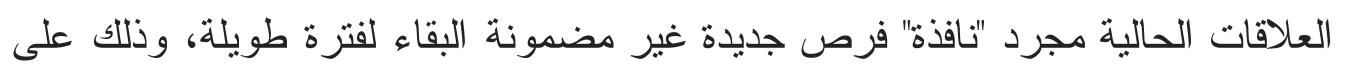

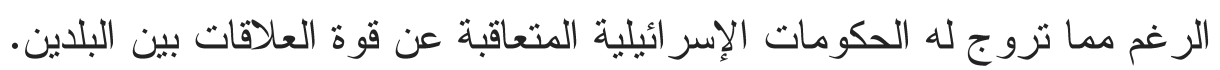

